\title{
Neuropathy and myopathy in two patients with anorexia and bulimia nervosa
}

\author{
R ALLOWAY, EH REYNOLDS, E SPARGO, GFM RUSSELL \\ From the Maudsley Hospital, King's College Hospital and the Institute of Psychiatry, Denmark Hill, London, \\ $U K$
}

SUMMARY Two adolescent patients with eating disorders and severe weight loss presented with neuromyopathy. The first was female and had a twenty months' history of bulimia nervosa with weight loss and episodic gorging and vomiting. The second was male with a two-year history of anorexia nervosa characterised by vegetarianism and increasing food restriction. Both had severe wasting and asymmetrical weakness of proximal limb muscles. The first patient deteriorated on refeeding and became temporarily paralysed. Both had a purpuric rash and haematological abnormalities. They made a complete recovery on a mixed diet: vitamin supplements were given to the first but not to the second patient.

Anorexia nervosa is a condition characterised by the following phenomena: a morbid attitude to weight and body size, severe weight loss and amenorrhoea in the female or loss of sexual interest and potency in the male. Bulimia nervosa, another category of eating disorder, shares some of the features of anorexia nervosa. In addition, the patient experiences episodic gorging of food and seeks to counteract any effect on weight by self-induced vomiting or laxative abuse or both.' Paradoxically, these conditions are associated with abundant activity; even when emaciated, patients may frequently continue normal activities and indeed take extra exercise. This phenomenon has been known for many years. ${ }^{23}$ In the later stages general fatigue is common: more rarely muscle weakness, due to hypokalaemia, occurs. It is at this stage that patients admit concern about their health. (For general review, see ref 4 ).

We report two adolescent patients, a bulimic girl and an anorexic lad, both severely underweight, in whom severe wasting and proximal muscular weakness were associated with haematological dysfunction and a diffuse purpuric skin rash. The proximal muscular weakness progressed to temporary paralysis in the bulimic girl. The similarity in presenta-

Address for reprint requests: Professor GFM Russell, Department of Psychiatry, Institute of Psychiatry, De Crespigny Park, Denmark Hill, London SE5 8AF, UK.

Received 4 August 1984 and in revised form 5 February 1985. Accepted 9 February 1985 tion of both patients and the differences in their early response to treatment are discussed in relation to their method of inducing weight loss.

\section{Case 1:}

A 17-year-old girl presented 20 months after the onset of weight loss. Prior to her illness she had weighed $65 \mathrm{~kg}$. She had intended to follow a weight reducing diet but later this alternated with uncontrollable gorging and vomiting. Two weeks before her admission to a general hospital, she had noticed weakness and difficulty in climbing stairs at school; moreover, she had become too weak to vomit.

On the first admission to the general hospital (fig 1) she weighed only $36 \mathrm{~kg}$ and had lost a further $3 \mathrm{~kg}$ before being transferred to the Maudsley Hospital. There the patient was found to be grossly emaciated (fig 2) with a dry skin coloured by a diffuse purpuric rash (fig 3 ) covering her trunk, back and upper thighs. Her parotid glands were enlarged. She was tachypnoeic at rest but otherwise her respiratory system was normal. Her pulse was $80 / \mathrm{min}$ and the blood pressure $90 / 60 \mathrm{~mm} \mathrm{Hg}$. Lanugo hair covered her back and arms. She had two ischaemic ulcers on her right forearm and left foot. Neurological examination revealed severe muscle wasting and weakness of the proximal limb girdles. She was unable to flex her neck, raise her hands above her shoulders, stand from a sitting position or sit up from a lying position unaided. Once standing, she could walk with an unsteady gait. Distal limb power from the wrists and ankles was normal. There was no ocular, facial, pharyngeal or tongue weakness. All arm and knee reflexes were diminished: ankle jerks were absent and plantar responses were flexor. Sensory examination, including vibration sense at the ankles, was normal. Initial haematological tests showed a normal haemoglobin level and blood count except that the platelets were low at $107 \times 10^{3} / \mathrm{mm}^{3}$. 

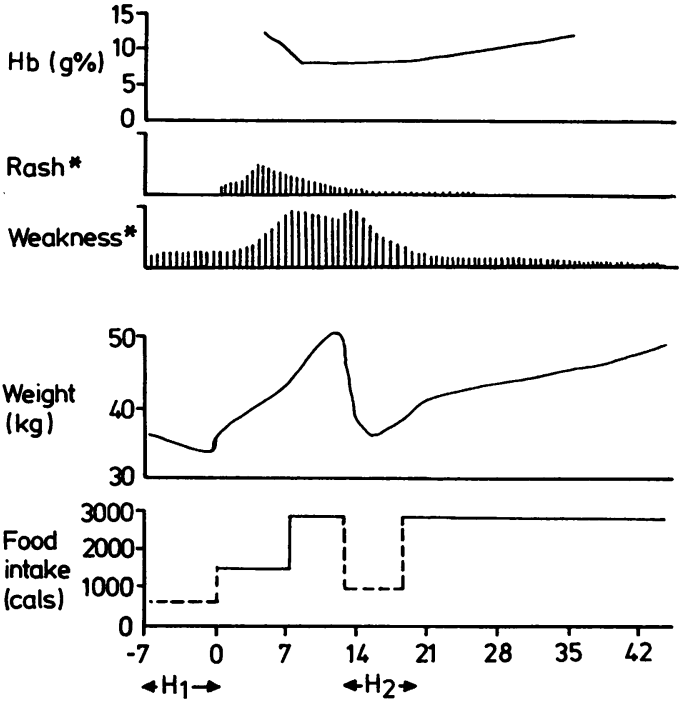

Time after admission to the Maudsley Hospital (weeks)

Fig 1 Graphical representation of the sequence of changes in body weight, muscular weakness, skin rash and haemoglobin with calorie intake in the bulimic girl (patient 1). ("measure of severity from physical examination. Hb Haemoglobin. $\left\langle H_{1}>\right.$ Admission to first general hospital; $\left\langle\mathrm{H}_{2}\right\rangle$ Admission to second general hospital.)

Plasma creatine kinase was $638 \mathrm{iu} / \mathrm{l}$. The prothrombin time was normal, as was liver function apart from mild hyperbilirubinaemia $(23 \mathrm{mmol} / \mathrm{l})$. The following plasma levels were normal: urea, electrolytes, calcium, T.4 and T.3. Serum Vitamin $B_{12}$ was normal and folic acid was $2.8 \mathrm{mg} / \mathrm{l}$. An electrocardiogram and chest radiograph were normal. Further investigations showed a negative Paul Bunnell test; blood cultures, electron microscopy of stool for viruses and antibody titres did not identify a pathogen. Serum levels of Vitamin E and magnesium were normal. Serum iron was $26 \mu \mathrm{mol} / 1$ and iron binding capacity (IBC) 32 $\mu \mathrm{mol} / \mathrm{l}$. Urinary and faecal porphyrins were not abnormal.

On the day of admission to the Maudsley Hospital (Day 0 , fig 1) the patient was commenced on a 1,500 calorie diet which was increased to 3,000 calories on Day 7. On Day 4 she was started on daily high potency vitamin $B$ and $C$ injections (Parentrovite) with oral folic acid (10 mg mane) and vitamin $\mathrm{E}$ ( $20 \mathrm{mg}$ three times a day). From Day 10 all vitamins were given orally (Vitamin $B$ and $C$ as Multivite) with, in addition, calciferol 6,000 units daily.

On Day 3 her physical condition started to deteriorate. Pitting oedema developed rapidly up to her waist and she gained $12 \mathrm{~kg}$ over the next 10 days. Urine output fell to less than $600 \mathrm{~m} /$ day from Day 7 to Day 11 . The rash spread and muscle weakness progressed to paralysis of the lower limbs, requiring two-hourly turning in bed. Liver function deteriorated: alkaline phosphatase rose to 201 $\mathrm{iu} / \mathrm{l}$, aspartate transaminase to $151 \mathrm{iu} / \mathrm{l}$ and glutamyl transpeptidase to $37 \mathrm{iu} / \mathrm{l}$ with total serum protein falling to $50 \mathrm{~g} / 1$ (albumen $30 \mathrm{~g} / \mathrm{l}$ ). On Day 4 the platelet count was un- 


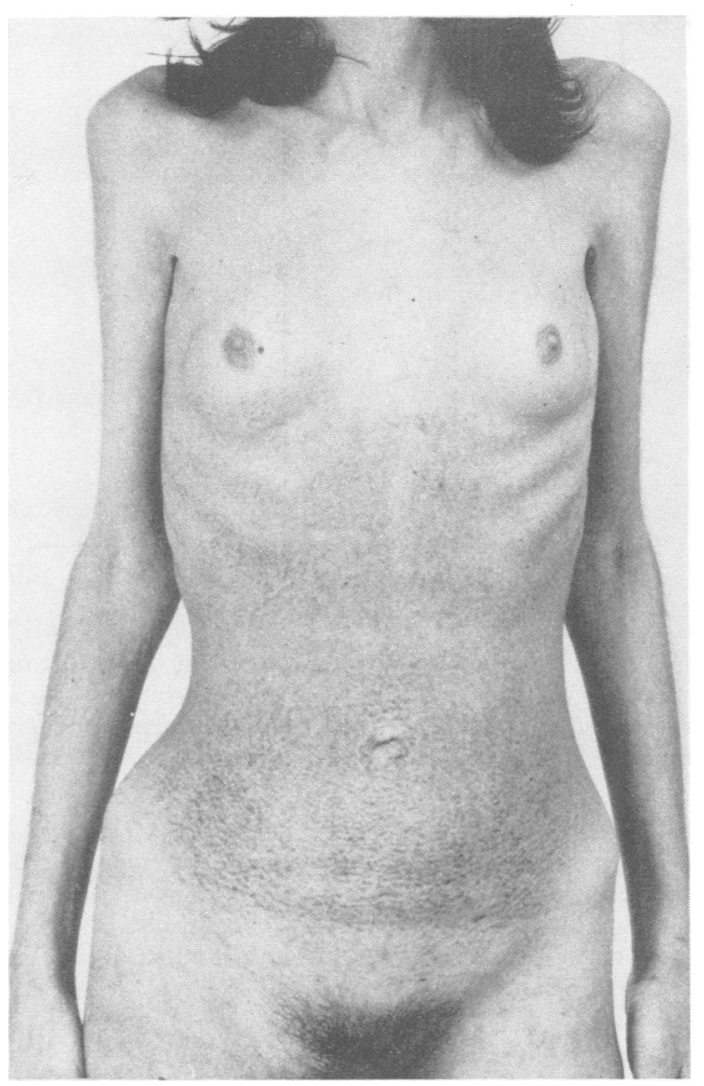

Fig 3 The anterior truncal view to show more detail of the purpuric skin rash.

recordable. Plasma electrolytes including potassium remained normal throughout the course of the illness.

From Day 14 the patient's physical state improved: muscle power and reflexes improved steadily and were almost normal one month later. This was accompanied by a gradual reduction in creatine kinase which was normal by Day 19. By Day 21 her rash had gone. A spontaneous diuresis occurred on Day 14 corresponding to the sharp loss in weight shown in fig 1 . On that day the haemoglobin level reached a minimum of $8.4 \mathrm{~g} / \mathrm{dl}$ but it slowly rose thereafter while a reticulocytosis continued for 2 months. Over this time course liver function returned to normal.
The patient was discharged after 4 months, weighing $54 \mathrm{~kg}$.

Three electrophysiological studies were performed during the admission. The first electromyogram (EMG) was on Day 7, at the height of the patient's weakness. Deltoid, biceps brachii, vastus medialis and first dorsal interosseous were sampled. Myopathic changes in the proximal muscles were shown by an increased incidence of polyphasic potentials, mainly stable but with occasional increase in jitter. Interference patterns were dense and of normal amplitude. Neuropathic changes were found from nerve conduction studies (see table): the sural sensory action potential (SAP) was barely detectable; radial $(24 \mu \mathrm{V})$, median (14 $\mu \mathrm{V})$ and ulnar $(12 \mu \mathrm{V})$ SAPs were within the statistical range of normal but considerably smaller than would normally be recorded in a girl of this age and build. The mixed nerve potential recorded over the ulnar nerve trunk in the cubital sulcus $(22 \mu \mathrm{V})$ was reduced by any criteria. On the second examination on Day 21 deltoid and rectus femoris showed minor myopathic changes, the sural nerve SAP was now $7 \mu \mathrm{V}$ (normal minimum $10 \mu \mathrm{V}$ ) and the other potentials larger than before $(35 \mu \mathrm{V}, 35 \mu \mathrm{V}, 20 \mu \mathrm{V}, 35 \mu \mathrm{V})$. At the third examination 3 months later, when power and reflexes were normal, minimal myopathic change was still detectable in the deltoid, and nerve conduction was normal (sural SAP $20 \mu \mathrm{V}$ ).

Case 2:

A 16-year-old lad was admitted 2 years after he had become vegetarian and slowly restricted his food intake. For the last 4 months, weight loss had accelerated and for one week he had been too weak to get out of bed.

On admission he weighed $40.8 \mathrm{~kg}$ : an estimated healthy weight was $67 \mathrm{~kg}$. His skin was covered in a purpuric rash which he had noticed 2 weeks before. He had moderate proximal muscle weakness involving all four limbs and trunk. He had difficulty in maintaining his arms raised and was unable to stand up from a kneeling position. Distal power was normal. Biceps, triceps supinator and knee reflexes were diminished: both ankle jerks were normal and plantar responses were flexor. Sensation was normal. Haematological tests showed low platelets $123 \times 10^{3} / \mathrm{mm}^{3}$ and a slight reduction in serum iron and IBC. Plasma creatine kinase was $43 \mathrm{iu} / \mathrm{l}$. The following plasma levels were normal: urea, electrolytes (including potassium), calcium, vitamin $B_{1}$ and glucose: thyroid and liver function tests were normal. Red cell transketolase was $39 \mathrm{iu} / \mathrm{l}$ (normal range 35-90 iu/l) on the fifth day after admission but by then the patient had begun to accept food so that any abnormality might have been corrected.

Table Nerve conduction measurements in both patients performed on given days after admission, and in normals

\begin{tabular}{|c|c|c|c|c|}
\hline \multirow{2}{*}{$\begin{array}{l}\text { Action potential: } \\
\text { Sensory }(S A P), \text { Mixed nerve (MNAP) }\end{array}$} & \multirow{2}{*}{$\begin{array}{l}\text { Normal } \\
\text { values }\end{array}$} & \multicolumn{2}{|l|}{ Patient 1} & \multirow{2}{*}{$\begin{array}{l}\text { Patient } 2 \\
\text { Day } 10\end{array}$} \\
\hline & & Day 7 & Day 21 & \\
\hline $\begin{array}{l}\text { Left sural SAP } \\
\text { Right radial SAP } \\
\text { Right median SAP } \\
\text { Right ulnar SAP } \\
\text { Right ulnar MNAP }\end{array}$ & $\begin{array}{l}>10 \mu \mathrm{V} \\
>40 \mathrm{~m} / \mathrm{s} \\
>30 \mu \mathrm{V} \\
>20 \mu \mathrm{V} \\
>15 \mu \mathrm{V} \\
>30 \mu \mathrm{V}\end{array}$ & $\begin{array}{l}\text { barely } \\
\text { detectable } \\
24 \mu \mathrm{V} \\
14 \mu \mathrm{V} \\
12 \mu \mathrm{V} \\
22 \mu \mathrm{V}\end{array}$ & $\begin{array}{l}7 \mu \mathrm{V} \\
50 \mathrm{~m} / \mathrm{s} \\
35 \mu \mathrm{V} \\
35 \mu \mathrm{V} \\
20 \mu \mathrm{V} \\
35 \mu \mathrm{V}\end{array}$ & $\begin{array}{l}6 \mu \mathrm{V} \\
\overline{43} \mu \mathrm{V} \\
- \\
-\end{array}$ \\
\hline
\end{tabular}


On admission the patient received a 1,000 calorie diet. This was continued for three weeks and was then increased to 3,000 calories daily. Weight gain was steady between 1-2 kg per week without the pronounced oedema which had occurred in Case 1. His rash disappeared over the next four weeks and his muscle power steadily improved and was normal, with normal reflexes, within eight weeks. By Day 7 his platelet count was normal. His haemoglobin had fallen to $10.7 \mathrm{~g} / \mathrm{dl}$ at the end of the third week and his white cell count was $3,700 / \mathrm{mm}^{3}$. Both were normal by the end of the fourth week. Creatine kinase remained normal. He was discharged after four months at a weight of $62 \mathrm{~kg}$.

The investigations of the neuromuscular disorder included an EMG, the measurement of sensory action potentials and a muscle biopsy. The EMG in Week 2, at a time of moderate clinical improvement, showed some myopathic changes. Thus, there was an increase in the incidence of notched motor unit potentials, and on low frequency attenuation a mild, stable increase in the number of components, spread over a slightly increased duration. Slight neuropathic changes were shown by a reduced sural nerve SAP $(6 \mu \mathrm{V})$, but the radial SAP was normal $(43 \mu \mathrm{V})$ (See table). Both were of normal form and latency.

The muscle biopsy was performed in Week 6: this was taken from the left quadriceps muscle when the patient weighed $50 \mathrm{~kg}$. Figure 4 shows a section of the quadriceps muscle with atrophy of both type I and type II fibres, although this was more pronounced in type II fibres, virtually all of which were atrophic. There was no evidence of necrosis, inflammatory infiltrate or loss of fibres. Figure 5 represents the distribution of fibre size for each type of muscle fibre obtained from the biopsy sample. The majority of type II fibres have diameters less than the range (40-80 $\mu \mathrm{m})$ seen in normal adult muscle, confirming a selective type II atrophy. Quantitative morphometric

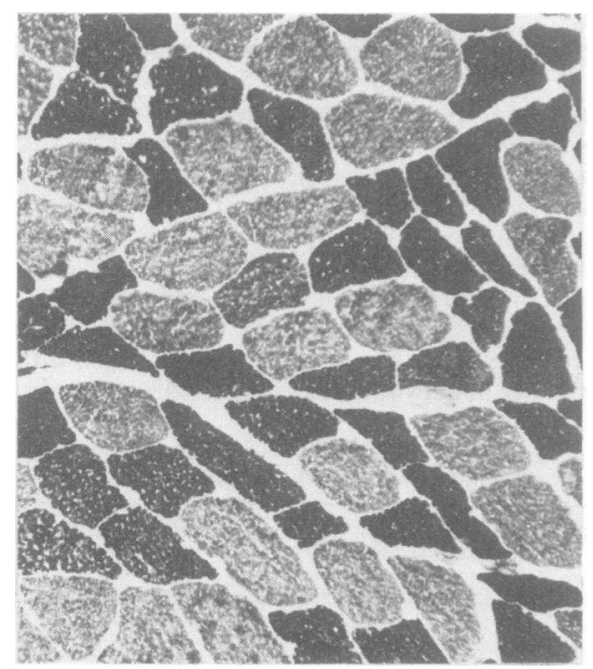

Fig 4 Cryostat section of left quadriceps muscle showing selective atrophy of type II fibres (dark). Myosin adenosine triphosphatase (ATPase) at pH $9.4 \times 150$.

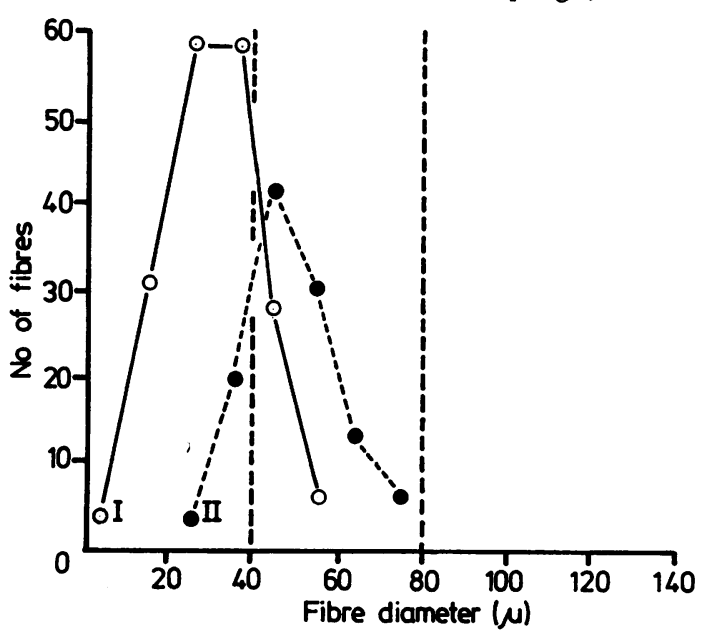

Fig 5 Distribution curves of fibre size in muscle biopsy in patient 2. Type I fibres $0 . .$. . Type II fibres $\bigcirc-\bigcirc$. The majority of type II fibres have diameters less than the range $(40-80 \mu)$ seen in normal adult muscle.

analysis showed normal proportions of fibre type (Type $九 \vec{\circ}$ $38 \%$; Type II 62\%). It also confirmed severe type II atrophy (mean diameter $35.1 \mu \mathrm{m} \pm 11.0$, compared with $\frac{\Phi}{\mathrm{D}}$ normal value of $65 \mu \mathrm{m}, 5$ and a slight atrophy of type $\$$ fibres (mean diameter $54 \cdot 0 \mu \mathrm{m} \pm 11 \cdot 7$, compared with the normal of $61 \mu \mathrm{m})$.

\section{Discussion}

Muscular weakness is not recognised as occurring in anorexic or bulimic patients unless hypokalaemia supervenes. Sletteb $\emptyset$ et $\mathbf{a l}^{\mathbf{6}}$ recently described wasting of skeletal muscles and reduction in size of muscle fibres from biopsy material in patients with anorexia nervosa, but none of them had a paresis on clinical examination. The complications found in the two patients described here have not hitherto been reported. Yet it is almost certain that they were the result of malnutrition.

The organ systems involved in both patients were neuromuscular, haemopoeitic and cutaneous. In the first patient who had bulimia nervosa the liver, cardiovascular and renal systems became involved after refeeding. Distinctive deterioration in her physical condition was an important difference between the two patients, in an otherwise very similar initial presentation. It is useful to discuss previous findings in patients with anorexia nervosa and other nutritional disorders, to see whether light can be shed on the mechanism underlying the clinical state.

The neuromuscular abnormalities in our two patients were those of a peripheral neuropathy and myopathy. Clinically the myopathy dominated. Evi- 
dence of it included proximal muscle wasting and weakness, diminished reflexes, EMG abnormalities, a raised creatine kinase (Case 1) and an abnormal muscle biopsy (Case 2). The results of the biopsy agreed with those of Norwegian investigators who showed predominant Type 2 muscle fibre atrophy in two series of women with anorexia nervosa who had severe weight loss. ${ }^{67}$ They thought it unlikely that the muscle atrophy was simply due to polyneuropathy. Dastur et al, ${ }^{8}$ looking at muscle changes in adults and children with protein malnutrition in Bombay, found that both types (1 and 2) of muscle fibre were smaller and myelinated nerves were reduced in size. The evidence for neuropathy in our patients was electrophysiological, but included absent ankle jerks in Case 1 . There were no sensory symptoms or signs in either patient. Our clinical and electrical evidence is in keeping with a myopathy and neuropathy as the underlying neuromuscular disorder in malnutrition. This could adequately be explained by a quantitative proteincalorie malnutrition but vitamin deficiency may have been a factor. Thiamine, pyridoxine, nicotinamide, vitamin $B_{12}$ and $E$ and folic acid deficiencies have all been implicated as possible causes of neuropathy. It is possible that, in the first patient, refeeding precipitated thiamine deficiency when the carbohydrate load increased the requirements and led to paralysis, tachycardia and breathlessness (for review, see ref 9). In her the long history of induced vomiting may have contributed to low thiamine levels: unfortunately it was not possible to confirm this biochemically. There have been a few reports of thiamine deficiency in anorexia nervosa: Handler and Perkin $^{10}$ reported a case of Wernicke's encephalopathy associated with anorexia nervosa. The observation of cardiovascular and neurological deterioration on refeeding of our patient are indications of its possible contributory role. There are two protective factors which may have prevented thiamine deficiency in our second patient. He was vegetarian and had not vomited to induce weight loss; also his calorie intake in the first three weeks of admission was lower than in Case 1. The contribution of the other $B$ vitamins to the neuropathy is uncertain. Vitamin $E$ and $B_{12}$ levels were normal. Serum folic acid was only slightly low in both patients.

The skin and haematological changes can be considered together. The purpuric rash in both patients, however, was difficult to explain in the presence of only minor thrombocytopenia on admission. In the first patient, but not in the second, the platelet count fell to a level consistent with purpura. In the second World War studies in the Warsaw Ghetto," Lubarsch described severe damage of capillary vessels leading to petechiae and oedema. It may be that, in our patients, protein malnutrition exacerbated by reduction in platelet levels caused the purpuric rash.

The haematological changes were of transient bone marrow aplasia causing thrombocytopenia, anaemia and leucopenia with a spontaneous recovery. Warren and van der Wiele ${ }^{12}$ looked at 42 adolescent girls with anorexia nervosa: $38 \%$ had white cell counts of less than $5,000 / \mathrm{mm}^{3}: 33 \%$ had pancytopenia (with platelets less than $52,000 / \mathrm{mm}^{3}$ ) and $7 \%$ had anaemia alone. Thirteen out of 42 cases had bone marrow biopsies: of these six were hypoplasic but, interestingly, four out of six had no peripheral blood abnormalities. One had pancytopenia and the other leucopenia. The hypoplasia of the marrow was also found in Mant and Faragher's study of six anorexic patients. ${ }^{13}$ They considered the thrombocytopenia unimportant in contrast to our impression that it contributed to the skin changes in our patients. They commented that red cell aplasia is a fairly common finding in marasmus and kwashiorkor, and protein depletion is considered to be the main cause either by inducing primary bone marrow abnormality or through reduced erythropoetin production. The pancytopenia of anorexia nervosa may be due to other nutritional deficiencies perhaps related to reduced fat and carbohydrate ingestion.

The opinion formed by Netherlands workers during the famine in $1944-45^{14}$ was that vitamin deficiency did not appear to be causally responsible for the disorder in their famine victims after nine months' severe malnutrition and that general refeeding was the most effective remedy.

The causes of the mild and transient liver and renal abnormalities in the first patient after refeeding are uncertain. No biopsies were performed. The report on the effects of starvation in the Western Netherlands $^{14}$ during 1944-1945 refers to the observations of Pompe who looked at liver biopsies of malnourished people and showed an absence of glycogen in 17 out of 22 cases with focal necrosis and hydropic swelling. In our patient an obstructive picture with some hepatocellular involvement is suggested by the raised alkaline phosphatase, glutamyl transpeptidase and aspartate transaminase. It is possible that this was due to liver dysfunction secondary to cardiac failure but refeeding may also have led to the development of a transient fatty liver.

Although it is rare for patients with anorexia and bulimia nervosa to become so acutely ill, the occurrence of two similar cases presenting to one clinical unit within 6 months, indicates that it may be more common than the absence of reports in the literature suggests. The presence of a purpuric rash may be a grave warning of impending decompensation and an 
indication of the degree of malnutrition. An adequate dietary history will reveal those patients protected from vitamin deficiency by "health food" with a conscious use of supplements. However, it seems probable that protein and carbohydrate deprivation are responsible for the most serious pathology and vitamin deficiency may only, as in the case of thiamine, be revealed on refeeding. The presence of vomiting over long periods may also have been a contributory factor. It was gratifying that both our patients recovered completely from the neuromyopathy within three months. The rash and haematological abnormalities remitted more rapidly. In the War studies on malnutrition 114 the course of recovery showed an average of $14 \mathrm{~kg}$ weight gain in 3 months; muscle tissue was regenerated by exercise and the neuropathy resolved slowly, leaving paresthesiae. These residua were not seen in our patients.

The severity of these patients' conditions and potential consequences, coupled with their rapid and complete recovery in hospital, is an important reminder of the need to admit and treat before rapid decompensation occurs. The need to refeed slowly, at a rate inversely proportional to the severity of weight loss is also emphasised.

The authors thank Dr R O'Brecht and Dr J Payan for the electrophysiological studies, Dr P Guha for the muscle biopsy report, and the Pathology Laboratories of the Maudsley and King's College Hospitals for the haemotology tests.

\section{References}

${ }^{1}$ Russell GFM. Bulimia nervosa, an ominous variant of anorexia nervosa. Psychol Med 1979;9:429-48.

${ }^{2}$ Gull WW. Anorexia nervosa (Apepsia hysterica, Anorexia hysterica). Transactions of the Clinical Society of London 1874;7:22.

${ }^{3}$ Lasegue, C. De Panorexie hysterique. Archives of General Medicine 1873;1:385. (Also On hysterical anorexia. Medical Times 1873;2:265.)

${ }^{4}$ Garfinkel PE, Garner DM. Anorexia Nervosa, a Multidimensional Perspective. New York: Brunner/Mazel 1982.

${ }^{5}$ Dubowitz V, Brooke MH. Muscle Biopsy. A Modern Approach. London: WB Saunders. 1973:74-102.

- Slettebø M, Lindboe CF, Askevold F. The neuromuscular system in patients with anorexia nervosa: electrophysiological and histologic studies. Clin Neuropathol 1984;3:217-24.

${ }^{7}$ Lindboe CF, Askevold F, Slettebø M. Muscle changes in skeletal muscle of young women with anorexia nervosa. Acta Neuropathol (Ber) 1982;56:299-302.

${ }^{8}$ Dastur DK, Daver SM, Manghani DK. Changes in Muscle in Human Malnutrition with an Emphasis on the Fine Structure in Protein-calorie Malnutrition. Progress in Neuropath. Vol. V. Zimmermann HH, ed. New York: Raven Press, 1979.

"Spillane JD, Riddoch G. Nutritional Disorders of the Nervous System. Edinburgh: E \& S Livingstone, 1947.

${ }^{10}$ Handler CE, Perkin GD. Anorexia nervosa and Wernicke's encephalopathy: an undiagnosed association Lancet 1982;2:771-2.

"Winick M, ed. Wiley Series Current Concepts in Nutrition: Hunger diseases. Vol. 7, 1979.

12 Warren MP, Van der Wiele, RL. Clinical and metabolico features of anorexia nervosa. Am J Obstet Gynecol 1973;117:435-49.

${ }^{13}$ Mant MJ, Faragher BS. The haematology of anorexia nervosa. Br J Haematol 1972;23:737.

14 Burger ECE, Drummond JC, Stanstead MR. eds. Mal? nutrition and starvation in Western Netherlands. Sept 1944-July 1945. The Hague General State Printing Offices. 1948. 